\title{
Number of total mortality, cardiovascular mortality and Chronic Obstructive Pulmonary Disease due to exposure with Nitrogen dioxide in Tehran during 2005-2014
}

\author{
Majid Kermani, $^{1,2}$, Mohsen Dowlati ${ }^{* 1}$, Ahmad Jonidi Jaffar ${ }^{1,3}$, Roshanak Rezaei Kalantari ${ }^{1,3}$
}

Received: 15 Feb, 2017; Accepted: 18 Apr, 2017

\begin{abstract}
Background \& Aims: Air pollution has adverse effects on human health and cause various diseases including cardiovascular disease and respiratory. Therefore this study with aim of study of Number of total mortality, cardiovascular mortality and Chronic Obstructive Pulmonary Disease due to exposure with Nitrogen dioxide in Tehran during 2005-2014 were performed.

Materials \& Methods: This study is a descriptive-analytic. At first hourly data were taken from Tehran environmental protection agency and Air Quality Control Company. Then validated according to the WHO guidelines and Statistical parameters for quantifying health effects were calculated in excel. Finally, assessment of cases total mortality with software was performed.

Results: The results showed that the number of total mortality caused by exposure to NO2 In the past decade is 15141 people. Also the total number of cardiovascular mortality in the past decade is 8480 people and the total number of Chronic Obstructive Pulmonary Disease in the past decade is 2454 people in 2005-2014 years.

Conclusion: Air pollution, especially nitrogen dioxide leads to mortality And Morbidity in a lot of people. According to the results of this study should such actions, policies and planning and management to reduce air pollution preparedness of hospitals and health centers, educating the public

Be done.
\end{abstract}

Keywords: Air pollution, total mortality, Chronic Obstructive Pulmonary Disease, Nitrogen dioxide

Address: Tehran. Hem mat high way-Iran University Medical Science -Research Center for Environmental Health Technology

Tel: (+98) 9124840377

Email: mohsendowlati.69@gmail.com

\section{Introduction}

Air pollution, caused by modern life, is considered as one of the great problems of large cities such as Tehran. It can be understood according to multiple studies that the phenomenon has significant environmental and health effects on human and the environment (1-5). Air pollution is known as a major reason for increased mortality in the world. So that the mortalities have reached from 800 thousand cases in 2000 to 7.3 million in 2012 . In the meantime, 65 percent of these mortalities relates to the continent of Asia.

Seeping into sensitive areas or deep in the lungs, air pollutants are causing respiratory diseases such as emphysema and bronchitis. They can also lead to the aggravation of cardiovascular diseases, increase utilization and hospital admissions and premature death

\footnotetext{
${ }^{1}$ Research Center for Environmental Health Technology, Iran University of Medical Sciences Tehran, Iran (Corresponding Author)

${ }^{2}$ Associate Professor of Environmental Health Engineering Department, School of Public Health, Iran University of Medical Sciences, Tehran, Iran

${ }^{3}$ Professor of Environmental Health Engineering Department, School of Public Health, Iran University of Medical Sciences, Tehran, Iran
} 
(6-8). According to World Health Organization report, in 2012, approximately 3.7 million people worldwide lose their lives due to air pollution (9). Nowadays, many major cities have faced the difficult situation of unfavorable air quality and air quality status is not suitable in many metropolitan cities, especially Tehran (10-17).Gaseous pollutants such as nitrogen dioxide $\left(\mathrm{NO}_{2}\right)$, sulfur dioxide $\left(\mathrm{SO}_{2}\right)$, ozone $\left(\mathrm{O}_{3}\right)$ and Carbon monoxide $(\mathrm{CO})$ also exert adverse effects on mortality which necessitates their reviewing (18-20). Nitrogen (NOx) and mainly nitric oxide (NO) are produced by high-temperature combustion processes such as the burning of fuels in motors of vehicles and power plants, which once the dispersion occurs, NO reacts relatively fast with oxygen or ozone and forms NO2. These reactions are dominant and known as secondary source of $\mathrm{NO}_{2}$ production and the deformation often occurs near the source of contamination.

It should be noted that the air inside as well as outside can be contaminated with high concentrations of $\mathrm{NO}_{2}$ because no air heaters and ovens emit significant amounts of pollutants (21). Reddish-orange $\mathrm{NO}_{2}$ (almost brown) has a boiling point of 21.2 degrees Celsius and the pressure is low which holds it in its gaseous state. The gas is a strong oxidant and corrosive and is lower respiratory tract simulator, physiologically. According to the results of studies, toxicity of $\mathrm{NO}_{2}$ is several times more than NO causing effects on humans such as changes in the tissues of the kidney, liver and heart after 2 hours at a concentration of $15 \mathrm{ppm}$. It reduces immunity against infectious diseases, susceptibility to bacterial and increased risk of viral infections (22).

The main mechanism of toxicity of $\mathrm{NO}_{2}$ has been attributed to intervene lipid peroxidation in the cell membrane and different effects of free radical on structural and functional molecules (21). According to the results of the studies, the main impact of $\mathrm{NO}_{2}$ on people who were exposed to these contaminants was respiratory allergy, usually occurs in concentrations more than 1,800 micrograms per cubic meter in healthy subjects and in concentrations of 200 to 500 micrograms per cubic meter in people with asthma (23) or chronic obstructive pulmonary disease (COPD) (24). There are different models to evaluate the effects of air pollutants on human health, most of which are EpidemiologicalStatistical and integrated air quality data at concentration intervals with epidemiological parameters such as relative risk, baseline incidence and the relative component and display the result in mortality. One of these models is AirQ 2.2.3 software where the information of connection- response of population exposure data has been combined and the expected health effects are estimated. AirQ is a specialized software that enables the user to assess the potential effects of specific pollutants on human in an urban area and specific time period. AirQ is composed of two distinct parts. The first part contains the number of cases and mortalities attributable to air pollution (based on risk estimates from Time Series studies) and the second is to estimate long-term exposure effects using life tables (based on the estimation of the risks from Cohort Studies) (25).

Tehran is among Iran's great metropolises where the level of air pollution has increased day after day and became more severe. It must be noted that the dense of pollution at the level of citizens respiratory is an alarm that increases cardiovascular diseases, pulmonary, cancer and warns the mortality. Given the current trends, the mortalities are expected to be increased in Tehran yearly and more attentions of officials and experts is necessary to control air pollution. One of the most important ways to control the air pollution in large cities is management programs in which the correct formulation of the program would not be possible without relying on sources of accurate information on the status of ambient air and its impact on human health. Given that the health effects by air pollution with the contaminations have not been investigated 
scientifically, this study analyzes the effects of $\mathrm{NO}_{2}$ on the health of the citizens of Metropolis Tehran over a ten-year process using a model and AirQ software.

\section{Materials and Methods}

This is a cross-sectional study and AirQ 2.2.3 software was used to assess the adverse effects of $\mathrm{NO}_{2}$ on the health of citizens in Tehran. The information of $\mathrm{NO}_{2}$ emissions was received both from environmental protection agencies and Tehran Air Quality Control Company in Microsoft Excel file format as hourly data.

The data validity should be examined in order to perform statistical analysis and using raw data, in which the criteria listed by World Health Organization (WHO) was used for the purpose. Some of these criteria include: the ratio between the numbers of valid data for the two seasons (warm and cold) should not be more than 2 , at least $75 \%$ of valid data must exist in order to achieve the average one-hour values from data with a shorter average time, at least $75 \%$ of one-hour data (18 hours) should exist and be valid to access the values of the eight-hour moving average form one-hour data, and etc. (25).Valid data, after discarding the invalid data, must be entered into the software, but it should be considered that the data are based on volume-volume(ppm) and since determining adverse health effects are associated with inhaled pollutants' mass in AirQ, the data were converted using Microsoft Excel with regard to temperature and pressure conditions and were written based on volume-weight $(\mu \mathrm{g} / \mathrm{m} 3)$. Pre-processing steps (including removal, sheeting pollutant and time integration to estimate the average) and secondary processing (including code writing, calculating the mean and modifying the condition) have been done after the conversion using Microsoft Excel, and finally the required statistics including annual mean, heating season average, cold season average, $98^{\text {th }}$ percentile, annual maximum, warm season maximum and cold season maximum have been measured, respectively in each of the studied years. Population information was taken from the Statistical Center of Iran to determine each year population, which is required to estimate the health effects of pollutants. Finally, related component, the number of mortalities and mortalities from cardiovascular and respiratory diseases caused by exposure to $\mathrm{O} 3$ pollutant are presented in both form of tables and graphs by entering the data processed results in Air Q. To calculate the health effects and consequences in the Air Q, two ways can be used:

1. The use of WHO default values for the grade incidence and relative risk ( $95 \%$ confidence intervals). The values are automatically displayed to run the program.

2. Replacement of the default values with the selfestimates of grade and relative risk $(95 \%$ confidence intervals) using regional and national epidemiological studies.

Because of diverse differences between Iran and Europe in the age pyramid, default data of the software cannot be used as for the European Community. For this purpose, relative risks calculated for the country have been used through literature review $(26,27)$

Table 1: values for relative risk and incidence of the use of models to suit different health effects of nitrogen dioxide $\underline{(26,27)}$

\begin{tabular}{|c|c|c|c|}
\hline & (Health effects) & Incidence & RR $(95 \% \mathrm{CI})$ per $10 \mu \mathrm{g} . \mathrm{m} 3 \mathrm{NO} 2$ \\
\hline \multirow[t]{2}{*}{ Death } & Overall mortality & 5.543 & $003.1(002.1-004.1)$ \\
\hline & Mortalities from cardiovascular disease & 231 & $004.1(003.1-005.1)$ \\
\hline Disease & $\begin{array}{l}\text { Hospitalization due to chronic } \\
\text { obstructive pulmonary }\end{array}$ & 4.101 & $0026.1(0006.1-0044.1)$ \\
\hline
\end{tabular}

* The numbers in parentheses represent the low and high limits of relative risk 


\section{Results}

The results of this study include statistical parameters about concentration of nitrogen dioxide in Tehran during 2005-2014 and the results obtained from the application tables and charts are provided in this section. After validation of the data received from Air Quality Control and the Department of Environment in accordance with the standards of WHO, the number of stations with valid data for the analysis of nitrogen dioxide in Tehran during 2005-2010 were respectively as $5,6,6,5,8,15,11,25,9$ and 21 stations selected from 11 stations in 2005, 14 stations in 2006, 14 stations in 2007, 15 stations in 2008, 18 stations in 2009, 37 stations in 2010, 36 stations in 2011, 42 stations in 2012, 35 stations in 2013 and 33 stations in 2014, respectively. After primary and secondary processing of raw data, the required measures for the model are calculated, determined and presented in Table 2.

Table 2: Indicators necessary to assess the effects of $\mathrm{NO}_{2}$ and the ratio of average annual concentration $(\mu \mathrm{g} / \mathrm{m} 3)$ to standards during 2005-2014

\begin{tabular}{|c|c|c|c|c|c|c|c|c|c|c|}
\hline Parameter & 2005 & 2006 & 2007 & 2008 & 2009 & 2010 & 2011 & 2012 & 2013 & 2014 \\
\hline Annual average & 95 & 108 & 166 & 205 & 126 & 131 & 92 & 86 & 101 & 96 \\
\hline Cold season average & 100 & 108 & 201 & 237 & 133 & 145 & 96 & 85 & 110 & 104 \\
\hline Warm season average & 90 & 109 & 132 & 174 & 119 & 117 & 89 & 86 & 92 & 88 \\
\hline Annual 98th percentile & 196 & 174 & 322 & 450 & 183 & 208 & 139 & 119 & 156 & 143 \\
\hline Annual maximum & 261 & 356 & 386 & 644 & 297 & 228 & 218 & 122 & 197 & 174 \\
\hline Cold season maximum & 261 & 356 & 386 & 644 & 297 & 228 & 173 & 122 & 197 & 174 \\
\hline Warm season maximum & 173 & 178 & 213 & 334 & 183 & 208 & 218 & 121 & 137 & 128 \\
\hline \multicolumn{11}{|c|}{ The ratio of average annual concentration $(\mu \mathrm{g} / \mathrm{m} 3)$ to standards } \\
\hline Standard $\mathrm{A}=40 \mu \mathrm{g} / \mathrm{m} 3$ & 2.37 & 2.72 & 4.15 & 5.13 & 3.15 & 3.28 & 2.32 & 2.15 & 2.52 & 2.4 \\
\hline StandardB $=100 \mu \mathrm{g} / \mathrm{m} 3$ & 0.95 & 1.08 & 1.66 & 2.05 & 1.26 & 1.31 & 0.92 & 0.86 & 1.01 & 0.96 \\
\hline
\end{tabular}

\footnotetext{
A: Iran national standard (ratified in 2009), Guidelines for WHO (2005), Europe Union standard (2012)

B: EPA's AirQuality National standards
}

Based on the results of AirQ, the number of additional items and related component to $\mathrm{NO}_{2}$ for overall mortalities, mortalities due to cardiovascular disease and hospitalizations due to chronic obstructive pulmonary disorder (COPD) have been estimated and are shown in Table 3. 
Table 3: Estimated values for the number of additional items and related component to $\mathrm{NO}_{2}$ for overall mortalities, mortalities due to cardiovascular disease and hospitalizations due to chronic obstructive pulmonary disorder during mentioned years

\begin{tabular}{|c|c|c|c|c|c|c|c|c|c|c|c|c|}
\hline Health consequences & & & & 85 & 86 & 87 & 88 & 89 & 90 & 91 & 92 & 93 \\
\hline \multirow{5}{*}{$\begin{array}{l}\text { The number of additional } \\
\text { items and related } \\
\text { component to NO2for } \\
\text { overall mortalities }\end{array}$} & Attributable & Upper limit & 3.3 & 3.83 & 6.06 & 6.91 & 4.43 & 4.67 & 3.2 & 2.95 & 3.52 & 3.32 \\
\hline & component & Middle limit & 2.5 & 2.9 & 4.61 & 5.27 & 3.36 & 3.54 & 2.42 & 2.23 & 2.66 & 2.51 \\
\hline & $(\%)$ & Lower limit & 1.68 & 1.95 & 3.12 & 3.58 & 2.26 & 2.39 & 1.62 & 1.5 & 1.79 & 1.69 \\
\hline & & Upper limit & 1456 & 1730 & 2778 & 3215 & 2092 & 2235 & 1555 & 1455 & 1758 & 1684 \\
\hline & Upper limit & Middle limit & 1101 & 1310 & 2116 & 2453 & 1586 & 1696 & 1175 & 1100 & 1330 & 1274 \\
\hline Related component (\%) & & Lower limit & 740 & 882 & 1432 & 1665 & 1069 & 1144 & 790 & 738 & 894 & 856 \\
\hline \multirow{6}{*}{$\begin{array}{l}\text { The number of additional } \\
\text { items and related } \\
\text { component to NO2for } \\
\text { mortalities due to } \\
\text { cardiovascular disease }\end{array}$} & & Upper limit & 4.10 & 4.74 & 7.46 & 8.49 & 5.48 & 5.77 & 3.97 & 3.67 & 4.36 & 4.12 \\
\hline & Extra cases & Middle limit & 3.3 & 3.83 & 6.06 & 6.91 & 4.43 & 4.67 & 3.2 & 2.95 & 3.52 & 3.32 \\
\hline & & Lower limit & 2.5 & 3.9 & 4.61 & 5.27 & 3.36 & 3.54 & 2.42 & 2.23 & 2.66 & 2.51 \\
\hline & Related & Upper limit & 767 & 910 & 1454 & 1679 & 1099 & 1174 & 819 & 767 & 926 & 887 \\
\hline & component & Middle limit & 618 & 735 & 1180 & 1366 & 889 & 950 & 661 & 618 & 747 & 716 \\
\hline & $(\%)$ & Lower limit & 468 & 556 & 899 & 1042 & 674 & 721 & 449 & 467 & 565 & 541 \\
\hline The number of additional & The number & Upper limit & 3.62 & 4.19 & 6.62 & 7.55 & 4.85 & 5.11 & 3.51 & 3.24 & 3.85 & 3.64 \\
\hline items and related & of additional & Middle limit & 2.17 & 2.52 & 4.02 & 4.6 & 2.92 & 3.08 & 2.10 & 1.94 & 2.31 & 2.18 \\
\hline component to $\mathrm{NO} 2$ for & cases (cases) & Lower limit & 0.51 & 0.59 & 0.95 & 1.10 & 0.69 & 0.73 & 0.49 & 0.45 & 0.54 & 0.51 \\
\hline hospitalizations due to & Related & Upper limit & 297 & 353 & 566 & 655 & 427 & 456 & 318 & 297 & 359 & 344 \\
\hline chronic obstructive & component $(\%$ & Middle limit & 178 & 212 & 344 & 399 & 257 & 275 & 190 & 178 & 215 & 206 \\
\hline pulmonary disorder & ) & Lower limit & 41 & 50 & 82 & 95 & 60 & 65 & 44 & 41 & 50 & 48 \\
\hline
\end{tabular}

AirQ model is plotting a graph for the concentration intervals of pollutants for individual health effects which demonstrates the health effect of pollutants in contact with various concentrations of pollutants. Due to the high number of charts, graphs of the early years and end years of the study (Figures 1 to 6) are satisfied. As shown in Figures 1 to 6, there are three curves in each graph that the curves were drawn based on relative risks (upper, middle and lower limits) shown in Table 1.

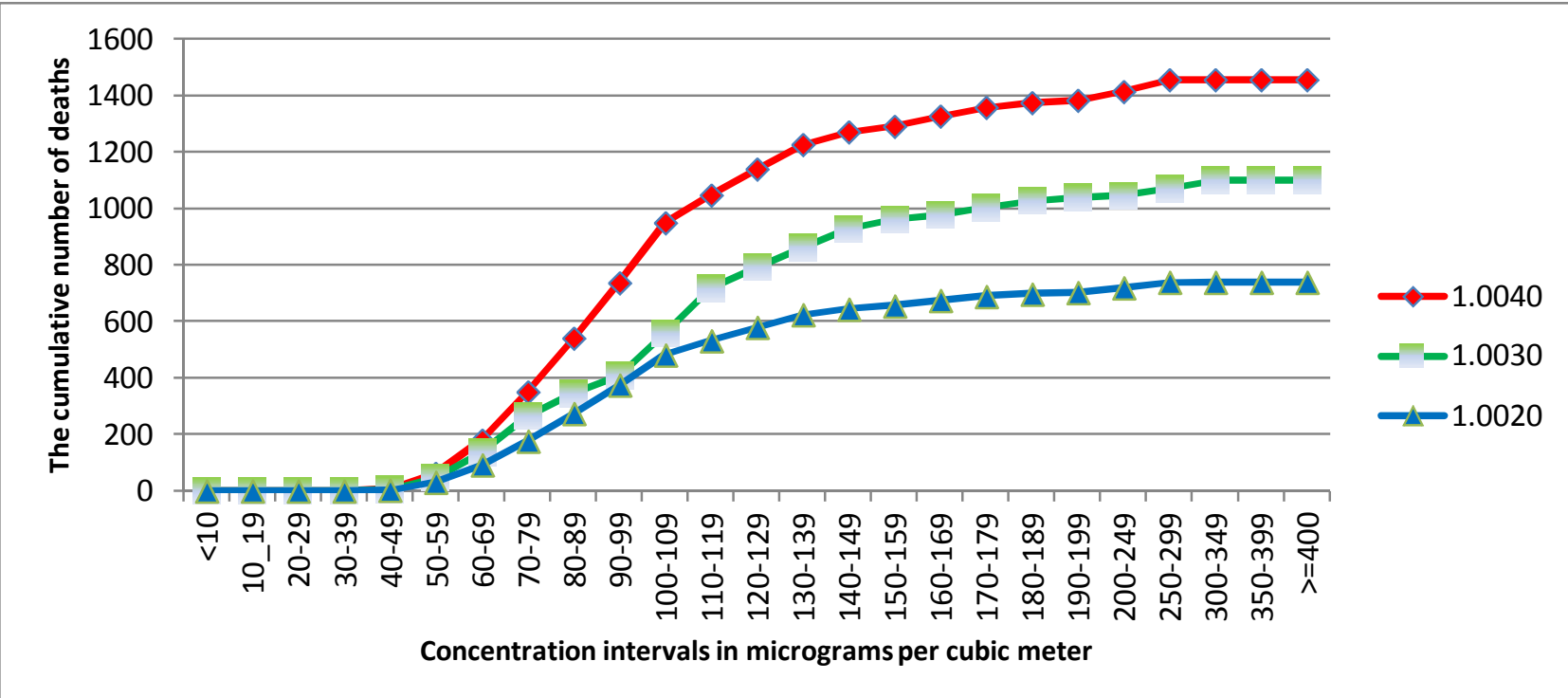

Graph 1: Cumulative cases of death from the NO2 against concentration intervals in 2005 


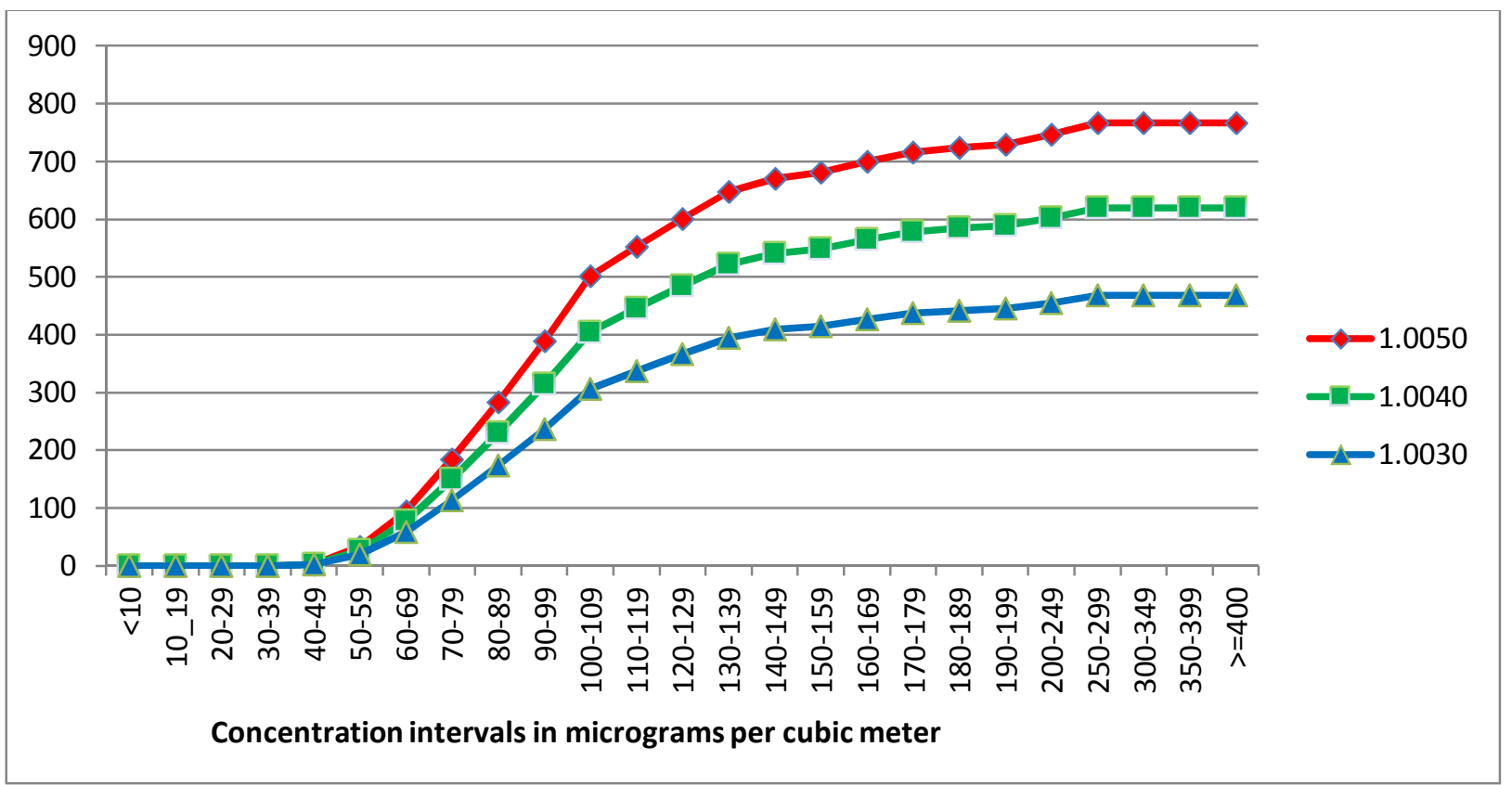

Graph 2. Cumulative number of cardiovascular mortalities caused by NO2 against concentration intervals in 2005

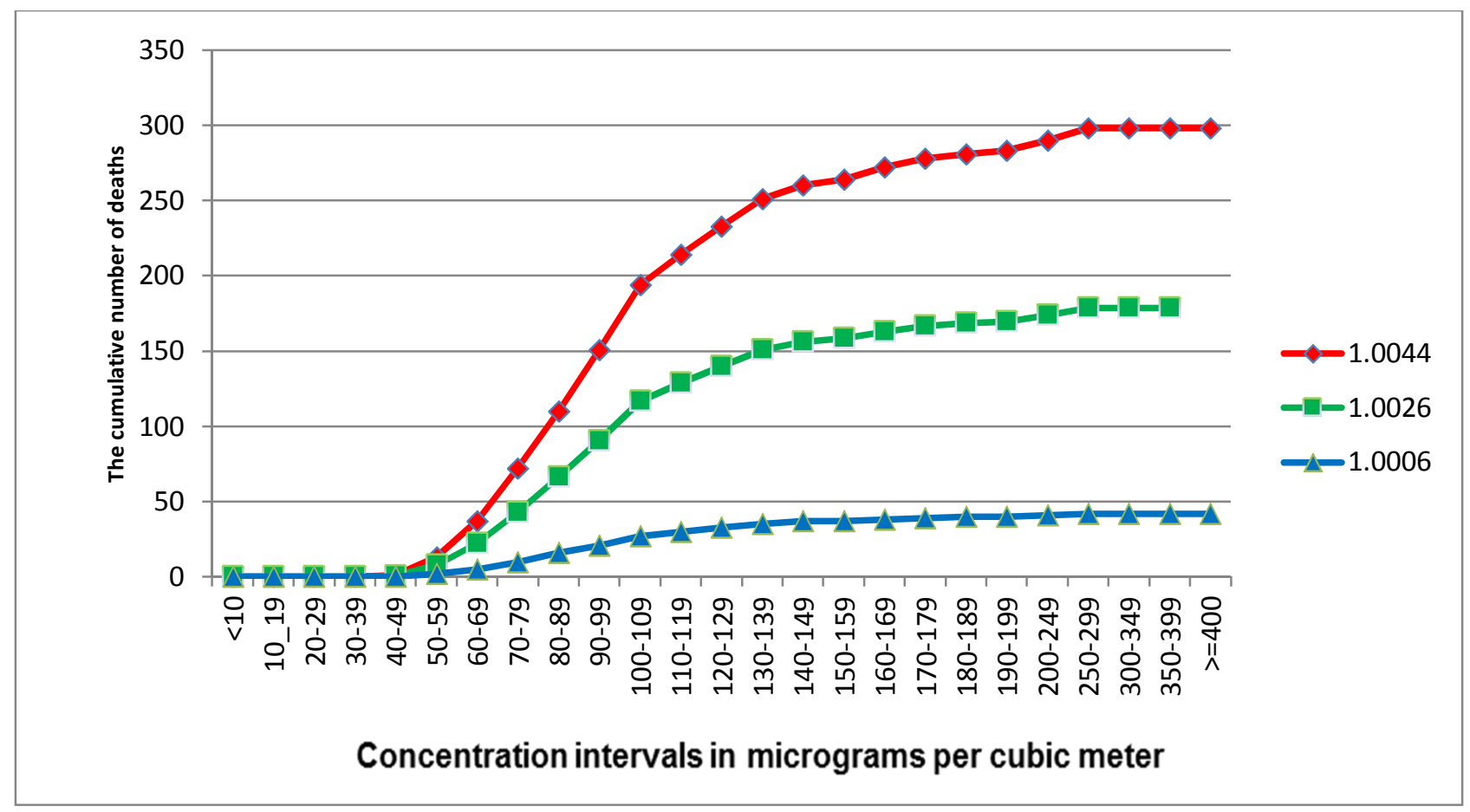

Graph 3. Cumulative number of hospitalization due to chronic obstructive pulmonary caused by NO2 against concentration intervals in 2005 


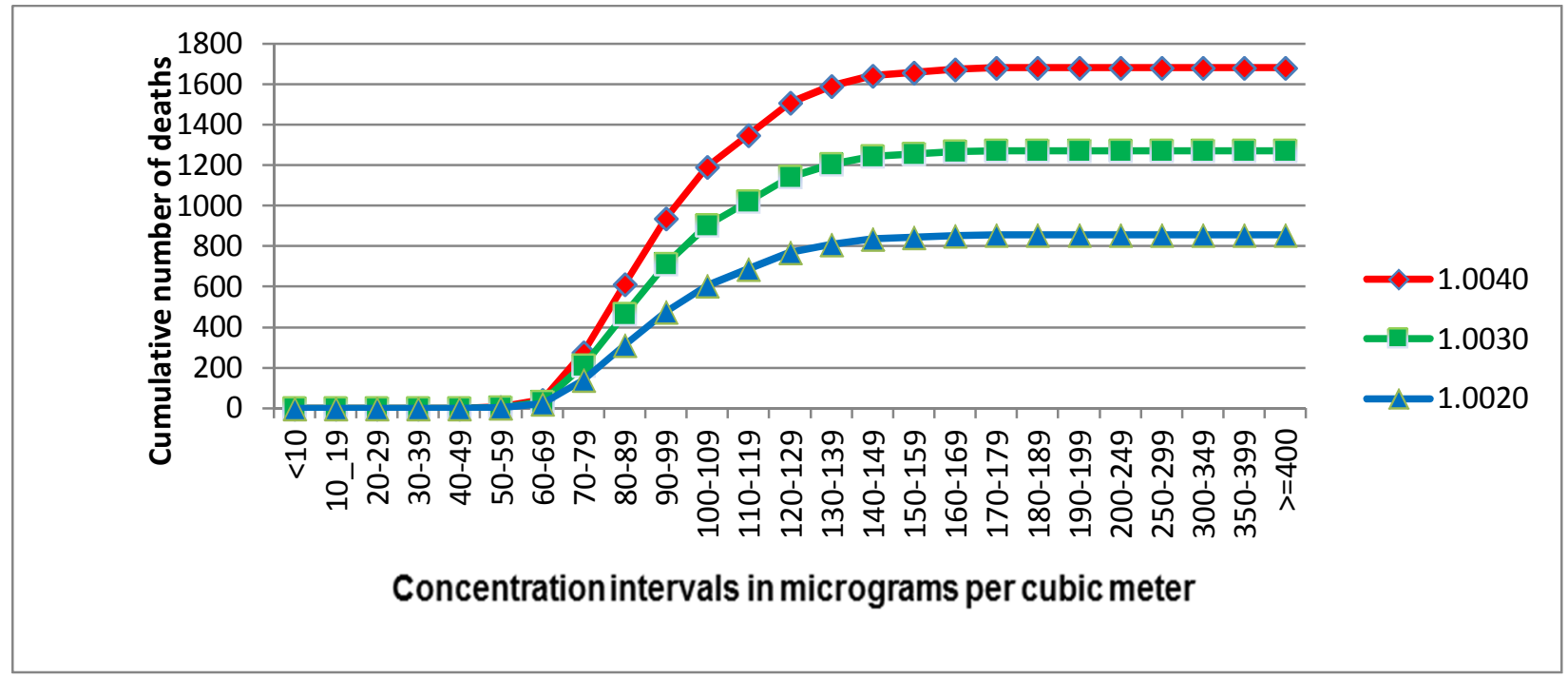

Graph 4. Cumulative number of overall mortalities caused by NO2 against concentration intervals in 2014

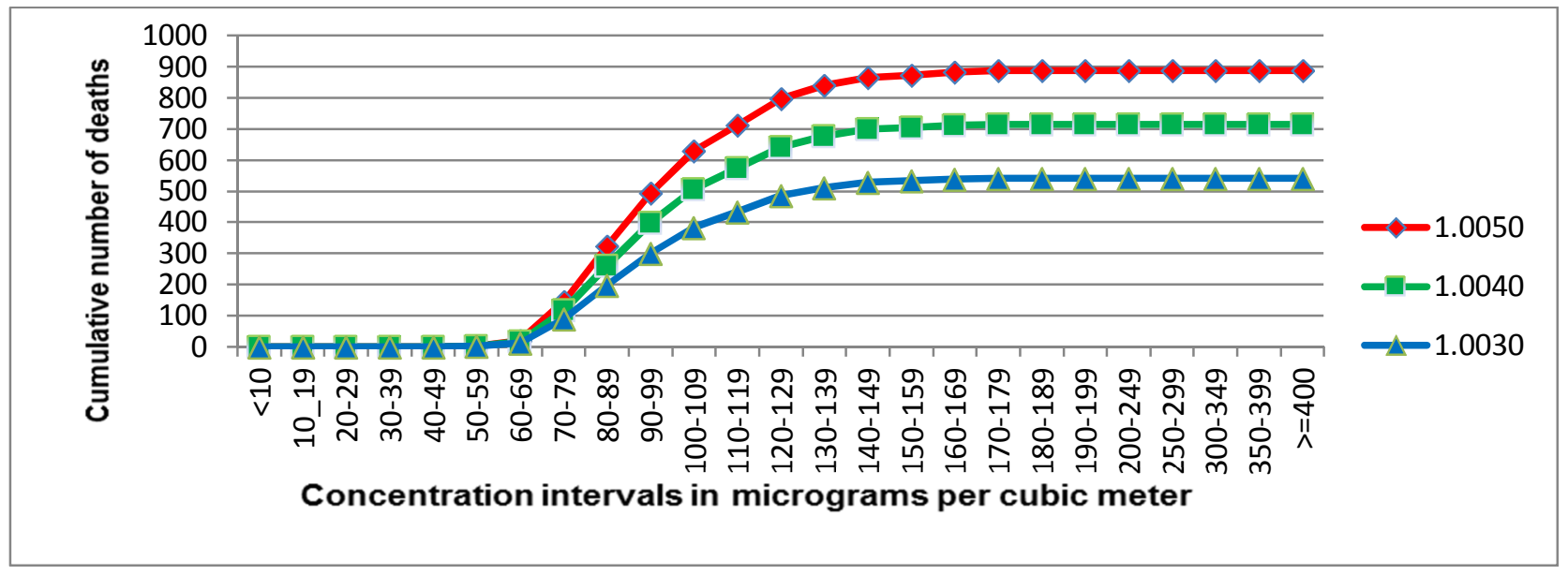

Graph 5. Cumulative number of cardiovascular mortalities caused by NO2 against concentration intervals in 2014

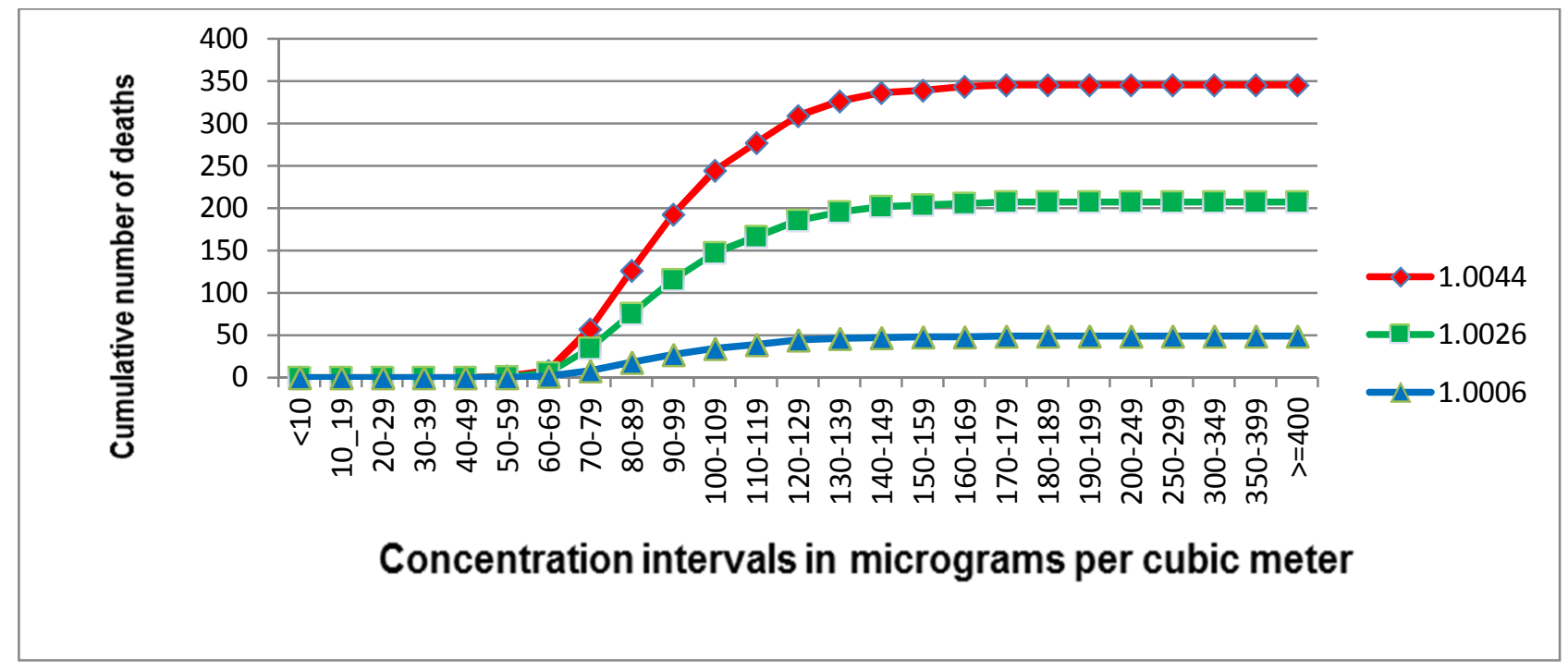

Graph 6. Cumulative number of hospitalization due to chronic obstructive pulmonary caused by NO2 against concentration intervals in 2014 


\section{Conclusion}

It can be seen, according to Table 2, that the average concentration of $\mathrm{NO}_{2}$ in cold season was more than warm season over the studied ten years which is linked to high consumption of fuel by cars, use of gas by homes for heating and etc. and also, non-destruction of produced $\mathrm{NO}_{2}$ due to lack of sunlight in winter. Compared to the annual average concentrations of guidelines and standard values (Table 2), it is determined that the annual average of $\mathrm{NO}_{2}$ concentration was above the standard level over the research years and the need for further studies about its effects on health is identified. In a study on five megacities in Iran during 2011, Bahrami et,al showed that the average annual concentration of $\mathrm{NO}_{2}$ in the cold season in all the examined cities was more than warm season. Furthermore, average annual concentrations were above the standard level in all cities and has been the guiding values (1). In considering the total number of mortalities, 2007 and 2008 have the most relative component and the highest number of cumulative total death with grade incidence equal to 543.5 cases per hundred thousand and the relative risk of 1.003. Death by cardiovascular disease with baseline incidence of 231 cases per hundred thousand people and the relative risk of 1.004 and hospitalization due to chronic obstructive pulmonary with baseline incidence of 101.4 people per hundred thousand people and the relative risk of 1.0026 had the highest relative component in2008 and the highest cumulative number of cardiovascular death and referring to hospital emergency due to chronic obstructive pulmonary disease were as1366 and 399 people, respectively. In a study by Ghanbari et al. in 2014 entitled "The effect of exposure to $\mathrm{NO}_{2}, \mathrm{O}_{3}, \mathrm{SO}_{2}$ on hospitalization due to chronic obstructive pulmonary in Tabriz ", showed that there is a direct correlation between exposure to gas pollutants and respiratory diseases and chronic obstructive pulmonary, so that 32 ,
69 and 15 hospitalization cases have been observed due to chronic obstructive pulmonary disease during a year in Tabriz (28). This can be due to the high number of vehicles, increased traffic and subsequently nonstandard fuel highly consumption in vehicles, high permanent and temporary population in Tehran. During the study by Burnett et al, conducted for 14 years in Toronto, Canada, the average annual number of hospital admissions due to chronic obstructive pulmonary disease were about 8 people that $40.4 \%$ has been reported because of exposure to $\mathrm{NO}_{2}(29)$.

Goudarzi and his colleagues used AirQ model to assess the health effects of $\mathrm{NO}_{2}$ in Tehran in 2008 and reported that the concentrations of $\mathrm{NO}_{2}$ over 60 micrograms per cubic meter relate to3.4 percent of all mortalities, cardiovascular and heart diseases and hospital admissions due to chronic lung disease (30). Touloumi and colleagues also reported a significant relationship between $\mathrm{NO}_{2}$ and the daily mortalities (31). The results indicate the adverse effects of $\mathrm{NO}_{2}$ on health. A single pollutant can act as an indicator of a pollutant mixtures. $\mathrm{NO}_{2}$ can be considered as an indicator of other produced pollutants such as particulate matter from the exhaust of vehicles. Population growth causing excessive development of factories without environmental considerations, and increased use of fossil fuels are the main reasons of air pollution increment. Generally, the statistics related to the number of mortalities, cardiovascular disease and chronic obstructive pulmonary clearly indicate the effects of air pollution on the health of citizens; hence there is a need for proper and effective planning to control and reduce the harmful effects of air pollutants, especially $\mathrm{NO}_{2}$.

Quantification of the effects attributed to air pollution determines the impact of air pollutants on population, and clearly shows the critical situation of air quality. Obtaining a direct relationship between exposing to different concentrations of the pollutants 
and their effects on human health is very difficult. The method is one of the validated methods used to assess health effects attributed to air pollution. The results of this study and software output show that the cumulative number of mortalities, mortalities by cardiovascular disease, and hospitalization due to chronic obstructive pulmonary disease caused by air pollution involves a lot in Tehran and the decision-makers and authorities should operate functional, sustainable and feasible solutions and strategies to reduce and control air pollution in Tehran metropolis based on studies and scientific research.

\section{References}

1. Bahrami Asl F, Kermani M, Aghaei M, Karimzadeh S, Salahshour Arian S, Shahsavani A, et al. Estimation of Diseases and Mortality Attributed to NO2 pollutant in five metropolises of Iran using AirQ model in 2011-2012. J Mazandaran Univ Med Sci 2015;24(121):239-49. (Persian)

2. Fallah jokandan S, Kermani M, Aghaei M, Dolati M. Estimation the Number of Mortality due to cardiovascular and respiratory disease, Attributed to pollutants O3, and NO2 in the Air of Tehran. J Health Res Community 2016;1(4):1-11. (Persian)

3. kermani $m$, aghaei $m$, bahramiasl $f$, gholami $m$, Fallah jokandan S, dolati m, et al. Estimation of cardiovascular death, myocardial infarction and chronic obstructive pulmonary disease (COPD) attributed to $\mathrm{SO} 2$ exposure in six industrialized metropolises of Iran. Razi J Medical Sciences. 2016;23(145):12-21. (Persian)

4. Kermani M, Aghaei M, Gholami M, Bahrami asl F, Karimzade SA, Falah S, et al. Estimation of Mortality Attributed to PM2.5 and CO Exposure in eight industrialized cities of Iran during 2011. Iran Occup Health J 2016;13(4):52-61. (Persian)

5. kermani M, dowlati M, A JONIDI JAFARI A, A REZAEI R. Study the number of cases cardiovascular mortality

\section{Acknowledgments}

Present article is part of a research project entitled "Assessment of health effects of air pollution on the number of mortalities, cardiovascular and respiratory diseases in Tehran metropolis and analysis of air quality indicators during 2005-2014 ", adopted by University of Medical Sciences and health services in Iran in 2014, code number 25455, which has been implemented by University of Medical Sciences. The authors deem themselves necessary to thank and appreciate the cooperation of respected authorities of Tehran quality control Company and Tehran environmental Protection Bureau for data collection.

Attributed to $\mathrm{CO}$ in Tehran in during a five-year. Rahavard Salamat J 2016;2(3):38-47. (Persian)

6. Chaaban F. Air quality. In: Tolba MK and SaabNW, Editor Arab environment: future challenges. Technical Publications and Environment \& Development Magazine. 2008:45-62.

7. Larsen B, others. Cost assessment of environmental degradation in the Middle East and north Africa region: selected issues. Economic Research Forum, working paper [Internet] 2011 [cited 2017 Jul 13]. Available from: http://erf.org.eg/wp-content/uploads/2014/08/583.pdf

8. Wark K WC, Davis WT Air pollution Its origin and control. New York: Addison Wesley Longman Press; 1998.

9. Younusian M. Air pollution epidemiology, studies and the ahead challenges science and health. The Sixth National Epidemiology Conference, Tehran: 2010. p. 34 5. (Persian)

10. Kermani M, Dowlati M, Jonidi Jafari A, Rezaei Kalantari R, Sadat Sakhaei F. Effect of Air Pollution on the Emergency Admissions of Cardiovascular and Respiratory Patients, Using the Air Quality Model: A Study in Tehran, 2005-2014. Health in Emergencies and Disasters Quarterly 2016;1(3):137-46. 
11. Kermani M, Dowlati M, Jonidi Jafari A, Rezaei Kalantari R. Estimation of Mortality, Acute Myocardial Infarction and Chronic Obstructive Pulmonary Disease due to Exposure to O3, NO2, and $\mathrm{SO} 2$ in Ambient Air in Tehran. J Mazandaran Univ Med Sci 2016;26(138):96-107. (Persian)

12. Kermani M, Dowlati M, jonidi jaffari A, Rezaei kalantari R. A Study on the Comparative Investigation of Air Quality Health Index (AQHI) and its application in Tehran as a Megacity since 2007 to 2014. J Res Environ Health 2016;1(4):275-84. (Persian)

13. kermani m, Dowlati M, Jonidi Jaffari A, Rezaei Kalantari R. Comparative Investigation of air quality Health in Tehran metropolis based on air quality index over a period of five years (2011-2015). J Health Res Community 2016;2(1):28-36. (Persian)

14. Kermani M, Jokandan SF, Aghaei M, Asl FB, Karimzadeh S, Dowlati $M$, et al. Estimation of the Number of Excess Hospitalizations Attributed to Sulfur Dioxide in Six Major Cities of Iran. Health Scope 2016;5(4).

15. Kermani M, fallah jokandan s, Aghaei M, dowlati M. Estimation of cardiovascular death, myocardial infarction and chronic obstructive pulmonary disease (COPD) attributed to PM and SO2 in the air of Tehran metropolis. J Res Environ Health 2016;2(2):116-26. (Persian)

16. Kermani M, A Aghaei M, A Gholami M, A Bahrami asl F, A Karimzade S, A Falah S, et al. Estimation of Mortality Attributed to PM2.5 and CO Exposure in eight industrialized cities of Iran during 2011. Iran Occup Health J 2016;13(4):52-61. (Persian)

17. Motesaddi Zarandi S, Raei Shaktaie H, Yazdani Cheratee J, Hosseinzade F, Dowlati M. Evaluation of PM2.5 Concentration and Determinant Parameters on its Distribution in Tehran's Metro System in 2012. J Mazandaran Univ Med Sci 2013;22(2):37-46. (Persian)

18. Gryparis A, Forsberg B, Katsouyanni K, Analitis A, Touloumi G, Schwartz J, et al. Acute Effects of Ozone on
Mortality from the "Air Pollution and Health. Am J Respir Crit Care Med 2004;170(10):1080-7.

19. Katsouyanni K, Touloumi G, Spix C, Schwartz J, Balducci F, Medina S, et al. Short-term effects of ambient sulphur dioxide and particulate matter on mortality in 12 European cities: results from time series data from the APHEA project. Air Pollution and Health: a European Approach. BMJ 1997;314(7095):1658-63.

20. Schwartz J. Air pollution and hospital admissions for cardiovascular disease in Tucson. Epidemiology 1997;8(4):371-7.

21. Kelly FJ, Blomberg A, Frew A, Holgate ST, Sandstrom T. Antioxidant kinetics in lung lavage fluid following exposure of humans to nitrogen dioxide. Am J Respir Crit Care Med 1996;154(6):1700-5.

22. Hatami H. Integrated book of public health. Tehran: Arjmand publications; 2005. (Persian)

23. Folinsbee L. Does nitrogen dioxide exposure increase airways responsiveness? Toxicol Ind Health 1991;8(5):273-83.

24. Morrow PE, Utell MJ, Bauer MA, Smeglin AM, Frampton MW, Cox C, et al. Pulmonary performance of elderly normal subjects and subjects with chronic obstructive pulmonary disease exposed to $0.3 \mathrm{ppm}$ nitrogen dioxide. Am J Respir Crit Care Med 1992;145(2):291-300.

25. WHO. Quantification of health effects of exposure to air pollution: report on a WHO working group, Bilthoven, Netherlands 20-22 November 2000. 2001 [cited 2017 Jul 13]; Available from: http://apps.who.int/iris/handle/10665/108463.

26. Gholampour A, Nabizadeh R, Naseri S, Yunesian M, Taghipour H, Rastkari N, et al. Exposure and health impacts of outdoor particulate matter in two urban and industrialized area of Tabriz, Iran. J Environ Health Sci Eng 2014;12:27.

27. Naddafi K, Hassanvand MS, Yunesian M, Momeniha F, Nabizadeh R, Faridi S, et al. Health impact assessment of 
air pollution in megacity of Tehran, Iran. Iran J Environ Health Sci Eng 2012;9(1):28.

28. Ghanbari Ghozikali M, Heibati B, Naddafi K, Kloog I, Oliveri Conti G, Polosa R, et al. Evaluation of Chronic Obstructive Pulmonary Disease (COPD) attributed to atmospheric O3, NO2, and SO2 using Air Q Model (2011-2012 year). Environ Res 2016;144(Pt A):99-105.

29. Burnett RT, Smith-Doiron M, Stieb D, Cakmak S, Brook JR. Effects of particulate and gaseous air pollution on cardiorespiratory hospitalizations. Archives of Environmental Health: An Int J 1999;54(2):130-9.
30. Goudarzi G, Naddafi K, Mesdaghinia A. Quantifying the health effects of air pollution in Tehran and determination of the third axis Integrated program effects to reduce the effect of air pollution in Tehran. (Dissertation). Tehran: Tehran University of Medical Scinces; 2009. (Persian)

31. Touloumi G, Katsouyanni K, Zmirou D, Schwartz J, Spix C, de Leon AP, et al. Short-term effects of ambient oxidant exposure on mortality: a combined analysis within the APHEA project. Am J Epidemiol 1997;146(2):177-85. 